Full length article

\title{
The effect of laser surface melting on grain refinement of phase separated $\mathrm{Cu}-\mathrm{Cr}$ alloy
}

\author{
Litian Zhang ${ }^{\mathrm{a}, \mathrm{b}}$, Gang $\mathrm{Yu}^{\mathrm{a}, \mathrm{b}, *}$, Shaoxia $\mathrm{Li}^{\mathrm{a}}{ }^{\mathrm{b}}$, Xiuli $\mathrm{He}^{\mathrm{a}, \mathrm{b}}$, Xiaoyu Xie ${ }^{\mathrm{a}, \mathrm{b}}$, Chunyang Xia ${ }^{\mathrm{a}}$, \\ Weijian Ning ${ }^{a}$, Caiyun Zheng ${ }^{\mathrm{a}}$ \\ a Institute of Mechanics, Chinese Academy of Sciences, Beijing 100190, China \\ ${ }^{\mathrm{b}}$ School of Engineering Science, University of Chinese Academy of Sciences, Beijing 100049, China
}

H I G H L I G H T S

- Laser surface melting (LSM) was first used to modify Cu-50Cr electric contacts.

- Average size of $\mathrm{Cr}$ grain decreased from $\sim 100 \mu \mathrm{m}$ to $\sim 1 \mu \mathrm{m}$.

- Laser processing parameters were optimized to obtain desirable microstructure.

- Coarsening effect of liquid phase separation was inhibited by high cooling rate.

- Mechanical and electrical properties of LSM contacts were significantly improved.

\section{A R T I C L E I N F O}

\section{Keywords:}

Laser surface melting (LSM)

Microstructure

Grain refinement

Liquid phase separation (LPS)

Interruption capability

\begin{abstract}
A B S T R A C T
Grain refinement and homogenization of $\mathrm{Cr}$ phase were achieved by laser surface melting (LSM) method, and the properties of $\mathrm{Cu}-\mathrm{Cr}$ alloy were significantly improved. In this study, LSM of Cu-50Cr alloy (wt.\%) was conducted with a high power density $\left(10^{6}-10^{7} \mathrm{~W} / \mathrm{cm}^{2}\right)$ laser beam, the microstructure and the properties of melt layer were investigated. The size of $\mathrm{Cr}$ phase was effectively refined from hundreds of micron scale to several micron scale, and the average size of $\mathrm{Cr}$ particles decreased to a few hundred nanometers. High cooling rate effectively inhibited coarsening effect on the $\mathrm{Cr}$ particles during liquid phase separation. Spherical $\mathrm{Cr}$ particles were dispersed in the melt layer with a thickness of $165 \pm 20 \mu \mathrm{m}$. Microhardness was obviously enhanced and the maximum hardness was $232 \mathrm{HV}$, which was 2.8 times that of the substrate. Arc duration of the LSM treated contacts increased up to $18 \%$. The withstanding voltage of the fixed and the moving contact increased to $28.7 \%$ and $35.4 \%$, respectively. The results show that LSM is an effective method to refine the microstructure of Cu-Cr alloy, and it is a promising modification method for electrical $\mathrm{Cu}-\mathrm{Cr}$ vacuum contacts.
\end{abstract}

\section{Introduction}

In the past decades, laser surface melting (LSM) treatment has been used for various engineering materials or components on the surface instead of entirety treatment, with the merits of refined and homogenized microstructure, strong metallurgical bond, fast processing speed and high controllability. A high power density $\left(10^{4}-10^{7} \mathrm{~W} / \mathrm{cm}^{2}\right)$ laser beam can be used as a controllable heat source to melt the surface of the alloy and then followed by rapid cooling $\left(10^{3}-10^{8} \mathrm{~K} / \mathrm{s}\right)$ and solidification to improve the surface dependent properties [1,2]. Unlike other laser surface treatments, such as laser cladding or alloying, no changes of chemical compositions or material additions are involved or required in LSM. Although a number of researches were reported to refine the microstructure and improve the properties, i.e., austenitic steel [3], Ti-based alloys [4] by LSM. However, very few studies have been carried out on the LSM of Cu-Cr alloy.

$\mathrm{Cu}-\mathrm{Cr}$ alloys with high $\mathrm{Cr}$ content have been widely accepted as electric contact materials in nearly all the medium-voltage and highcurrent commercial vacuum interrupters (VIs) [5]. Similar to other Cubased liquid immiscible alloys, when the $\mathrm{Cu}-\mathrm{Cr}$ undercooled liquid below the $\mathrm{T}_{\text {sep }}$, the Cu-Cr melt separated into Cu-rich melt and $\mathrm{Cr}$ melt during liquid phase separation (LPS) [6,7]. Cu-Cr immiscible alloys are very promising self-assembled composites, especially, when the refined $\mathrm{Cr}$ spherical particles dispersedly uniformly in the $\mathrm{Cu}$ matrix [8]. But the differences in densities of the two components result in the microstructural segregation during LPS. Due to this, the application of the

\footnotetext{
* Corresponding author.

E-mail address: gyu@imech.ac.cn (G. Yu).
} 
$\mathrm{Cu}-\mathrm{Cr}$ alloys is limited. Therefore, some small-scale rapid solidification methods, for example, melt spinning [9], electromagnetic levitation and splat-quenching [7] were used to refine microstructure. LSM is a rapid solidification technique capable of large scale industrial production. However, LSM of Cu-Cr alloy was more challenging because of the high thermal conductivity and high reflectance of Cu-based alloys for laser. According to previous studies, the grain size of Al-based alloys with high thermal conductivity was refined to sub-micron scale using laser power density of $3.65 \times 10^{5} \mathrm{~W} / \mathrm{cm}^{2}$ [10]. Besides, the grain size of Cu-Al-Ni-Mn alloy was decreased to $23 \pm 5 \mu \mathrm{m}$ with the laser power density of $5.97 \times 10^{5} \mathrm{~W} / \mathrm{cm}^{2}$ [11]. The grain size was decreased with high laser power density by LSM method, it could be expected that a finer microstructure of $\mathrm{Cu}-\mathrm{Cr}$ alloy could be obtained similarly.

In this paper, the $\mathrm{Cu}-50 \mathrm{Cr}$ (wt.\%) contacts were melt on the surface by a high power density $\left(10^{6}-10^{7} \mathrm{~W} / \mathrm{cm}^{2}\right)$ laser beam to refine and disperse the $\mathrm{Cr}$ phase. The effect of LSM on the grain refinement of $\mathrm{Cu}$ $\mathrm{Cr}$ alloy, the influence of liquid phase separation (LPS) on the microstructure evolution, the influence of grain refinement on microhardness, withstanding voltage and the interruption capability of $\mathrm{Cu}-\mathrm{Cr}$ contacts were studied. This paper provides a new way to improve the performance of $\mathrm{Cu}-\mathrm{Cr}$ electrical contacts which has broad industrial application prospects.

\section{Experimental details}

\subsection{Material and laser surface melting (LSM)}

LSM treatments were conducted by a $1 \mathrm{~kW}$ continuous Nd:YAG laser with a wavelength of $1.064 \mu \mathrm{m}$. In an effort to establish the range of optimal lasing parameters, a series of experiments have been carried out at laser power density from $10^{6} \mathrm{~W} / \mathrm{cm}^{2}$ to $10^{7} \mathrm{~W} / \mathrm{cm}^{2}$ with laser scanning speed from 6000 to $10,000 \mathrm{~mm} / \mathrm{min}$. The scanning interval between adjacent scanning tracks was kept $0.08 \mathrm{~mm}$ and the surface of the sample was continuously scanned in lines that were equal to the length of the samples. In order to control thermal stress and cool the back of the contact, a clamping device with a water cooling circulating system was made to hold the sample. The temperature of the back of the sample remained at $15{ }^{\circ} \mathrm{C}$ to get a sharper temperature gradient from the surface to the bottom. The LSM process was protected in an $\mathrm{Ar}$ atmosphere box (gas content: $\mathrm{O}_{2}<50 \mathrm{ppm}, \mathrm{H}_{2} \mathrm{O}<100 \mathrm{ppm}$ ). Schematic diagram of experimental set-up for LSM method was given in Fig. 1.

The investigated $\mathrm{Cu}-50 \mathrm{Cr}$ (wt.\%) alloys were prepared by PM method and the chemical composition, density, mechanical and physical properties were listed in Table 1 . The maximum solubility of $\mathrm{Cu}$ in $\mathrm{Cr}$ and $\mathrm{Cr}$ in $\mathrm{Cu}$ is $0.77 \%$ and $0.08 \%$ (mole fraction) at eutectic temperature, respectively. $\mathrm{Cu}-\mathrm{Cr}$ alloy is a binary pseudo-alloy composed of $\mathrm{Cr}$ particles embedded in $\mathrm{Cu}$ matrix.

\subsection{Characterization}

The samples after laser treatment were cut perpendicular to the scanning direction by electrical discharge wire cutting. The microstructure of the cross section was observed by an optical microscope and SEM (ZEISS EVO18 scanning electron microscope) equipped with an EDS (energy dispersion spectrometer). The mean diameter of the $\mathrm{Cr}$ particles were measured and calculated by Image-Pro software, average length of diameters measured at 2 degree intervals and passing through object's centroid. Hardness along the depth of the cross-section was measured by a Vickers hardness tester with a load of $100 \mathrm{~g}$ and a dwelling time of $15 \mathrm{~s}$. The measurements were performed on five lines at intervals of $30 \mu \mathrm{m}$ on the cross section of the LSM treated sample, the first line was tested on the line about $30 \mu \mathrm{m}$ below the surface of the melt layer. And ten points were tested on each line, each point was $50 \mu \mathrm{m}$ apart.

A pair of untreated and a pair of LSM treated contacts with the same
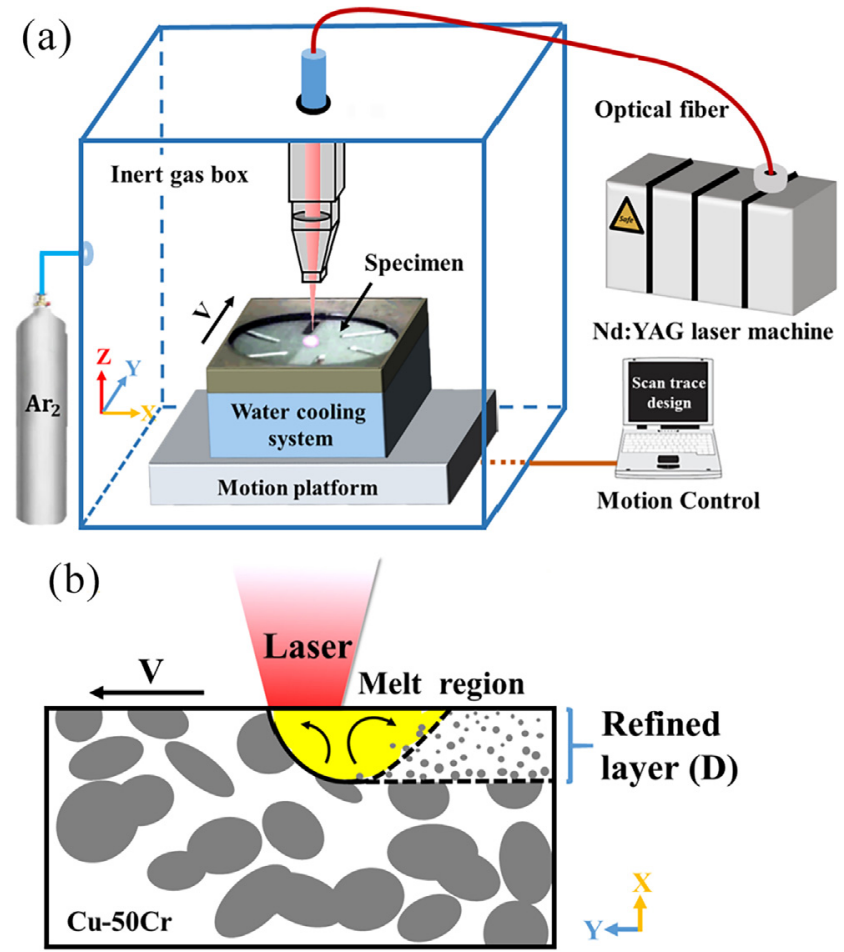

Fig. 1. (a) Schematic diagram of experimental set-up for LSM and (b) the principle diagram of interaction with $\mathrm{Cu}-\mathrm{Cr}$ alloy.

Table 1

Chemical composition, density, mechanical and physical properties of $\mathrm{Cu}-\mathrm{Cr}$ alloy contact.

\begin{tabular}{lllll}
\hline Element & $\begin{array}{l}\text { Composition } \\
\text { (wt.\%) }\end{array}$ & $\begin{array}{l}\text { Density }\left(10^{3}\right. \\
\left.\mathrm{kg} / \mathrm{m}^{3}\right)\end{array}$ & $\begin{array}{l}\text { Geometrical } \\
\text { parameters (mm) }\end{array}$ & Hardness (HB) \\
\hline $\mathrm{Cu}$ & Bal. & $\geq 7.90$ & $\Phi 50 \times 2.8$ & 80 \\
$\mathrm{Cr}$ & $49-52$ & & \\
$\mathrm{O}$ & $\leq 0.05$ & & \\
$\mathrm{~N}$ & $\leq 0.004$ & & \\
\hline
\end{tabular}

processing parameters were symmetrically assembled in two vacuum interrupters (VIs), whose rated voltage was $12 \mathrm{kV}$, rated short-circuit breaking current was $31.5 \mathrm{kA}$. The withstanding voltage of these two VIs were tested with the contact gap of $2 \mathrm{~mm}$. The lightning voltages were applied to the contacts by an up-and-down method until the contacts broke down. The maximum value of the voltage was cited as the withstanding voltage. In order to reduce the destruction effects caused by standard lightning impulse voltage, the number of tests was limited to 20 times. Then the switching tests were performed in the two VIs. Parameters for the tests were as follows: voltage $23 \mathrm{kV}$, contact gap $11 \mathrm{~mm}$, transient recovery voltages (TRV peak up to $22 \mathrm{kV}, 4100 \mathrm{~Hz}$ ) were standardized to correspond to the values guided by the IEC 62271100 [12]. At the beginning of the experiment, the contacts were closed. During the high current range, the current exhibited a sinusoidal characteristic up to a maximum high current, between 5 and $10 \mathrm{kA}$. After arc ignition, the current was conducted until current zero at $10 \mathrm{~ms}$.

\section{Results}

\subsection{Microstructure characteristics}

Microstructure of the untreated Cu-50Cr alloy was shown in Fig. 2. The dark round or elliptical $\mathrm{Cr}$ particles were surrounded by the bright $\mathrm{Cu}$ phases. The key parameter for $\mathrm{Cu}-\mathrm{Cr}$ alloy, the average size of $\mathrm{Cr}$ 


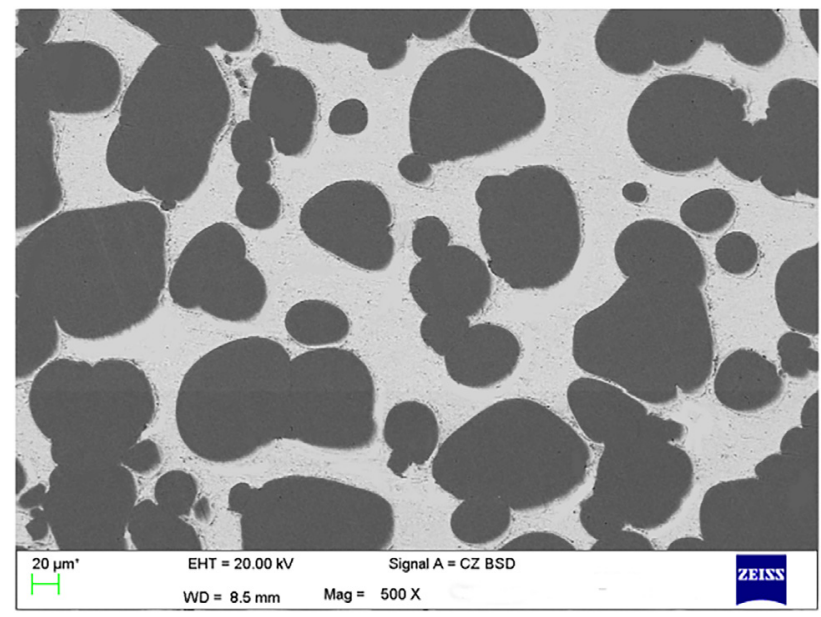

Fig. 2. Microstructure of Cu-50Cr alloy (backscattered electron images).

phase was approximately $84.9 \mu \mathrm{m}$.

Fig. 3a shows the cross-sectional microstructure of $\mathrm{Cu}-50 \mathrm{Cr}$ alloy after laser surface melting with laser power density $5.73 \times 10^{6} \mathrm{~W} / \mathrm{cm}^{2}$ and the scanning speed of $8000 \mathrm{~m} / \mathrm{min}$. The microstructure of the layer is obviously different from that of the matrix, and the interface between the layer and the matrix is clear. The thickness of the melt layer is $35 \pm 10 \mu \mathrm{m}$. The $\mathrm{Cr}$ phase in the melt layer is refined. However, the presence of many unmelt $\mathrm{Cr}$ band (labeled as A in Fig. 3a) implies that the laser power is insufficient to ensure the fully melt of $\mathrm{Cr}$ phase, which results in the inadequate refinement of the $\mathrm{Cr}$ particles.

Fig. 3b illustrates the cross-sectional microstructure of $\mathrm{Cu}-50 \mathrm{Cr}$ alloy after laser surface melting with laser power density of $7.26 \times 10^{6} \mathrm{~W} / \mathrm{cm}^{2}$ and the scanning speed of $6000 \mathrm{~mm} / \mathrm{min}$. The thickness of the melt layer was $215 \pm 30 \mu \mathrm{m}$. There are two kinds of morphologies of refined $\mathrm{Cr}$ phases in the melt layer. One corresponds to a small $\mathrm{Cr}$ spheroids and the other is a large $\mathrm{Cr}$ band with a strong curved and elongated pattern (labeled as B in Fig. $3 \mathrm{~b}$ ). The extension direction of $\mathrm{Cr}$ bands is to the upper part of melt pool. Since these two phases can be distinguished by contrast, it can be seen that the composition of the melt layer is uneven. The effect of strong stirring caused by convection on phase separated alloy melt can be seen, showing a strong swirling flow pattern with larger $\mathrm{Cr}$ bands (labeled as $\mathrm{C}$ in Fig. 3b). Fig. 3b illustrates the effect of excessive laser power on the formation of large amounts of $\mathrm{Cr}$ bands due to intense melt flow.

Fig. 4a presents the cross-sectional microstructure of $\mathrm{Cu}-50 \mathrm{Cr}$ alloy after laser treatment with laser power density $7.26 \times 10^{6} \mathrm{~W} / \mathrm{cm}^{2}$ and the scanning speed of $8000 \mathrm{~m} / \mathrm{min}$. The average thickness of the melt layer was $165 \pm 20 \mu \mathrm{m}$. At the bottom of the molten pool, a large number of small spherical $\mathrm{Cr}$ particles were observed dispersing in the melt layer, but only a small number of $\mathrm{Cr}$ sheets were observed. The typical element map distribution of cross section is shown in Fig. 4b. Because there are only two components in the alloy, the element distribution in the melt layer reflects the degree of refinement. According to the results of element distribution analysis, it can be clearly seen that the two elements ( $\mathrm{Cu}$ and $\mathrm{Cr}$ ) are uniformly mixed in the melt layer, while the two components in the matrix show a trend to separate. This sample is called LSM contact in the following to study the refinement of microstructure and related electrical properties of $\mathrm{Cu}-\mathrm{Cr}$ contacts.

Fig. 5 shows the magnified image of the morphologies of $\mathrm{Cr}$ grains in different regions of a single melt pool (marked in Fig. 4a) and the corresponding statistics of $\mathrm{Cr}$ grain size. As illustrated in Fig. 5a, massive $\mathrm{Cr}$ spheroids within the $\mathrm{Cu}$ matrix (Fig. 5a) with the average diameter of $\sim 0.59 \mu \mathrm{m}$ (Fig. 5e) dispersed near the surface. In the middle of the melt pool (Fig. 5b), numerous $\mathrm{Cr}$ spherical particles with a relatively larger diameter $\sim 0.79 \mu \mathrm{m}$ (Fig. $5 \mathrm{f}$ ) homogeneously distributed in the $\mathrm{Cu}$ matrix. Fig. $5 \mathrm{c}$ displays the overlapping zone, on the left side of the overlapped zone which was melt, cooled down and solidified to form a microstructure similar to that of the right side, but it was heated again. So the $\mathrm{Cr}$ grains in the overlapped region were larger than that of the right side which was only heated once. The mean diameter of $\mathrm{Cr}$ grains in this zone $(\sim 0.84 \mu \mathrm{m})$ was larger. The refined $\mathrm{Cr}$ particles were preferably distributed in the $\mathrm{Cu}$ matrix with a sphere or near sphere form. Additionally, a clustering tendency for the $\mathrm{Cr}$ spheroids to form bigger $\mathrm{Cr}$ clusters was observed on fusion line in the overlapped zone (Fig. 5c). Cr spheroids and only a few $\mathrm{Cr}$ sheets were observed in the region at the bottom of the melt pool, as shown in Fig. 5d. According to the micrographs and the statistics of $\mathrm{Cr}$ grain size, the size of refined $\mathrm{Cr}$ particles was slightly decreased with the increasing distance from the bottom to top of the melt pool. The majority of the $\mathrm{Cr}$ particles were all with almost round shape to minimize individual surface energy. And a few $\mathrm{Cr}$ sheets were observed only at the bottom of the melt pool. The average size of the Cr particles was from $\sim 1 \mu \mathrm{m}$ to almost $10 \mu \mathrm{m}$.

Fig. 6 showed the magnified image of Cr-rich particles in Fig. 5c, magnified image of $\mathrm{Cr}$ sheet in Fig. 5d and their corresponding EDS analysis. As labeled by A in Fig. 6a, many porous $\mathrm{Cr}$ particles composed of fine nano-sized $\mathrm{Cu}$ precipitates. As shown in Fig. $6 \mathrm{~b}$, the element content of the particle was similar to that of $\mathrm{Cu}_{27} \mathrm{Cr}_{73}$ (in mass ratio). Fig. $6 \mathrm{c}$ shows the $\mathrm{Cr}$ particle with a sheeted shape (labeled by B) containing a supersaturated $\mathrm{Cu}(40 \%)$ (Fig. $6 \mathrm{~d}$ ). The $\mathrm{Cr}$ content was rich in these particles, therefore, the $\mathrm{Cr}$ cluster and $\mathrm{Cr}$ sheet were $\mathrm{Cr}$-rich cluster and Cr-rich sheet in the present study, respectively.
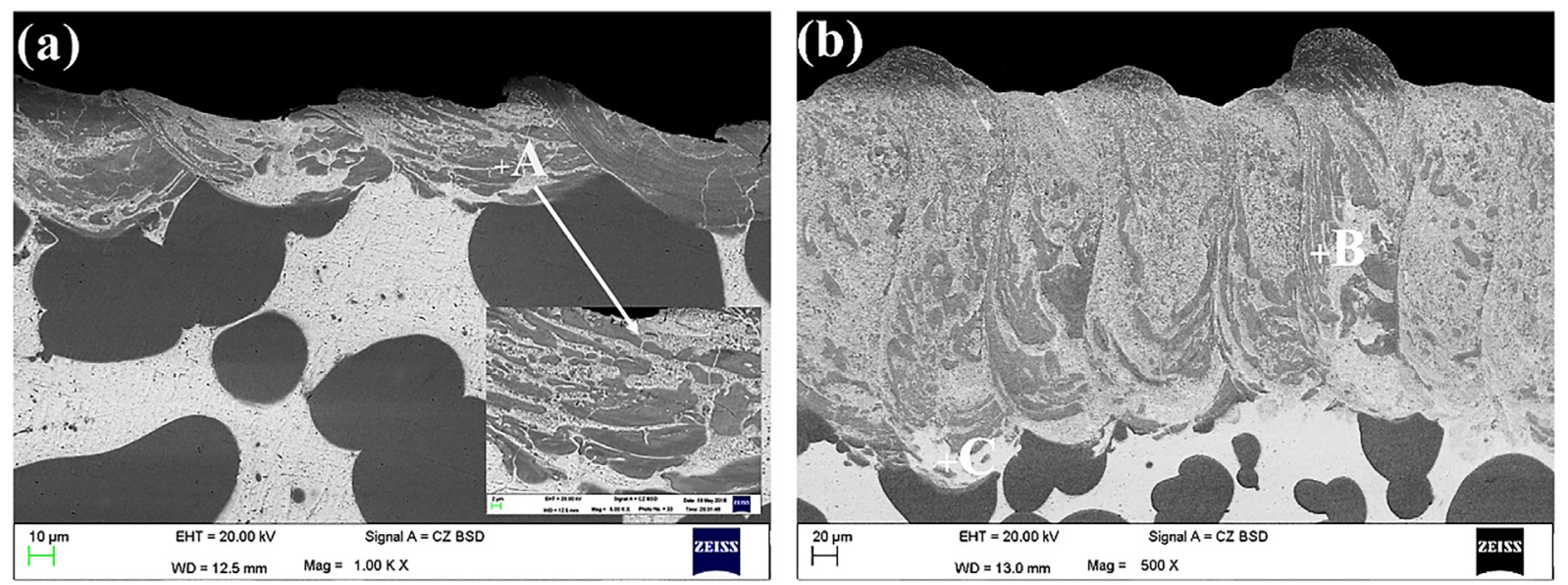

Fig. 3. Microstructure of the cross section of laser surface melt Cu-50Cr alloy with the laser power density (a) $5.73 \times 10^{6} \mathrm{~W} / \mathrm{cm}^{2}$ (b) $7.26 \times 10^{6} \mathrm{~W} / \mathrm{cm}^{2}$. 

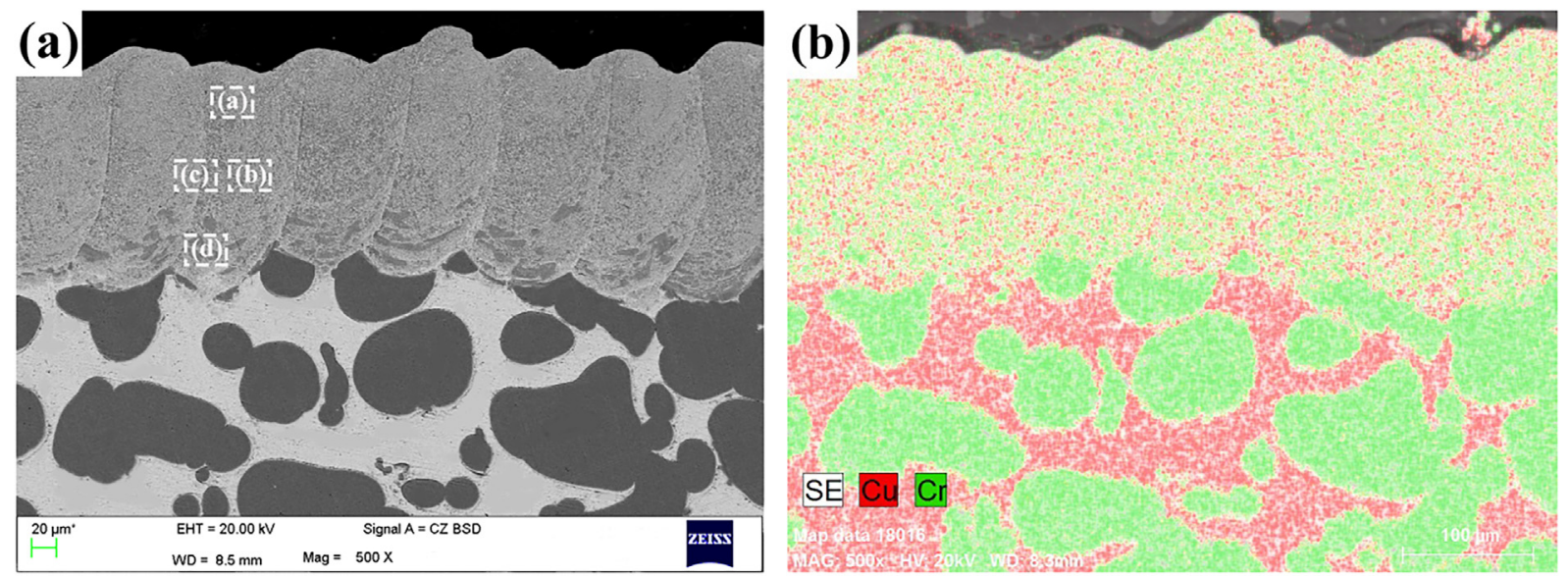

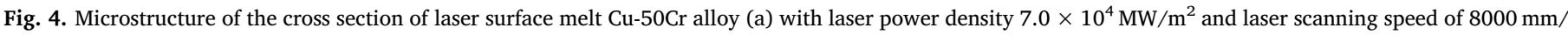

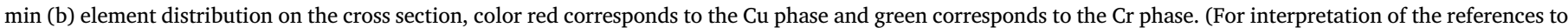
color in this figure legend, the reader is referred to the web version of this article.)

\subsection{Parametric results}

The laser power density was calculated by the following Eq. (1), the interaction time $(\mathrm{t})$ was calculated by the following Eq. (2), and the laser beam fluence (E) was calculated based on the following Eq. (3):

$\mathrm{Q}=\frac{P}{\pi r_{B}}$

$\mathrm{t}=\frac{2 r_{B}}{v}$

$\mathrm{E}=Q \cdot t=\frac{2 P}{\pi r_{B} v}$

where $P$ is laser power, $r_{B}$ is the radius of laser spot and $v$ is the laser scanning speed. Fig. 7a shows the effect of $Q$ on the depth of the refined layer, the thickness of refining layer is proportional to power density $(\mathrm{Q})$. When given a certain value of $\mathrm{Q}$, the longer the interaction time $(\mathrm{t})$, the more energy the surface absorbed during LSM. It was apparent that the thickness of the refined layer was directly related to the interaction time within the appropriate range of $\mathrm{Q}$ given here. When the $\mathrm{Q}$ was higher than $5.0 \times 10^{4} \mathrm{MW} / \mathrm{m}^{2}$, the refined $\mathrm{Cr}$ melt layer could be observed. But when the $\mathrm{Q}$ was higher than $8.28 \times 10^{4} \mathrm{MW} / \mathrm{m}^{2}$, the effect of excessive $\mathrm{Q}$ resulted in non-uniform distribution of $\mathrm{Cr}$ phase. However, the properties of Cu-Cr alloy not only depended on the depth of the refined layer, but also on the size and distribution of the Cr grains. As the grain refinement of $\mathrm{Cu}-\mathrm{Cr}$ alloy depended both on the interaction time and laser power density, the effect of $\mathrm{E}$ on the refined layer was given in Fig. 7b. It has been found that the optimal range of $E$ is very narrow, between $4.3 \times 10^{3} \mathrm{~J} / \mathrm{cm}^{2}$ and $5.5 \times 10^{3} \mathrm{~J} / \mathrm{cm}^{2}$. It was insufficient to fully melt the $\mathrm{Cr}$ phase when the $\mathrm{E}$ was lower than that of the optimal range, leading to unmelt $\mathrm{Cr}$ bands. The intense melt flow resulted in the formation many large elongated $\mathrm{Cr}$-sheets when the $\mathrm{E}$ was higher than $5.5 \times 10^{3} \mathrm{~J} / \mathrm{cm}^{2}$. As shown in Figs. 4 and 5 , when the $\mathrm{E}=5.45 \mathrm{MJ} / \mathrm{m}^{2}$, which was in the optimal range, most of the spherical Cr particles were uniformly distributed in the melt layer, with only a few Cr-sheets appearing at the bottom of the melt pool.

\subsection{Property characteristics}

\subsubsection{Microhardness of the refined layer}

Fig. 8 illustrates the microhardness distribution of the refined layer. The hardness in the refined layer was well-distributed, while the difference of hardness was particularly large on the substrate. The uniformity in hardness distribution of the melt zone implied the homogenization of the microstructure. The hardness of the refined layer was from 188 to $232 \mathrm{HV}$ and the average hardness was approximately $220 \mathrm{HV}$.

However, the Vickers hardness measurement for the substrate was not appropriate. The size of the Vickers hardness indenter was much smaller than of the original $\mathrm{Cr}$ phase. As the Vickers hardness tested on the substrate shown in Fig. 8, when the indenter was pressed on different phases, the differences of the hardness was large. So the hardness of substrate was characterized by Brinell hardness. The Brinell hardness for $\mathrm{Cu}-50 \mathrm{Cr}$ substrate was $80 \mathrm{HB}$, about $82 \mathrm{HV}$. The average hardness of the refined layer $(220 \mathrm{HV})$ was much two times higher than that of the Cu-50Cr substrate (82HV).

\subsubsection{Withstanding voltage of $\mathrm{Cu}-50 \mathrm{Cr}$ contacts with refined layer}

Fig. 9 shows the top view of the untreated and LSM treated $\mathrm{Cu}-50 \mathrm{Cr}$ contacts. Fig. 10 shows the withstanding voltage values of these contacts. Fig. 10a and b is the experimental result of standard lightning impulse voltage applied to the fixed end and the moving end of untreated contacts, respectively. Fig. $10 \mathrm{c}$ and $\mathrm{d}$ is the experimental result of standard lightning impulse voltage applied to the fixed end and the moving end of contacts after LSM. Fifteen tests were conducted at each voltage level, both the voltage value and success rate were recorded. Generally, it is considered that three successive failures at the same voltage level are considered not to withstand the voltage level in the power industry. The withstanding voltage value of the fixed end $(+)$ and the moving end ( - ) for the untreated contacts is $101 \mathrm{kV}$ and $96 \mathrm{kV}$, respectively. The withstanding voltage value of the fixed end $(+)$ and the moving end $(-)$ for the LSM contacts is $130 \mathrm{kV}$. Compared with the untreated contacts, the withstanding voltage value of the fixed and the moving contact increased to $28.7 \%$ and $35.4 \%$, respectively. The results were in accordance with the expectations because LSM treatment provided grain refinement in the surface, which was responsible for the higher withstanding voltage observed.

\subsubsection{Interruption capability of $\mathrm{Cu}-50 \mathrm{Cr}$ contacts with refined layer}

As shown in Fig. 11, the LSM contacts passed all the successive 20 tests, while the untreated contacts failed 4 times. The average arc duration of the LSM untreated sample $(5.3 \mathrm{~ms})$ increased up to $18 \%$ than that of the untreated samples $(4.5 \mathrm{~ms})$. Both the max and min arc duration of LSM sample were higher than the untreated (Table 2). And the arc duration of LSM contacts remained relatively stable which fluctuated slightly around $5.3 \mathrm{~ms}$. However, the arc duration of the untreated contacts fluctuated greatly. 

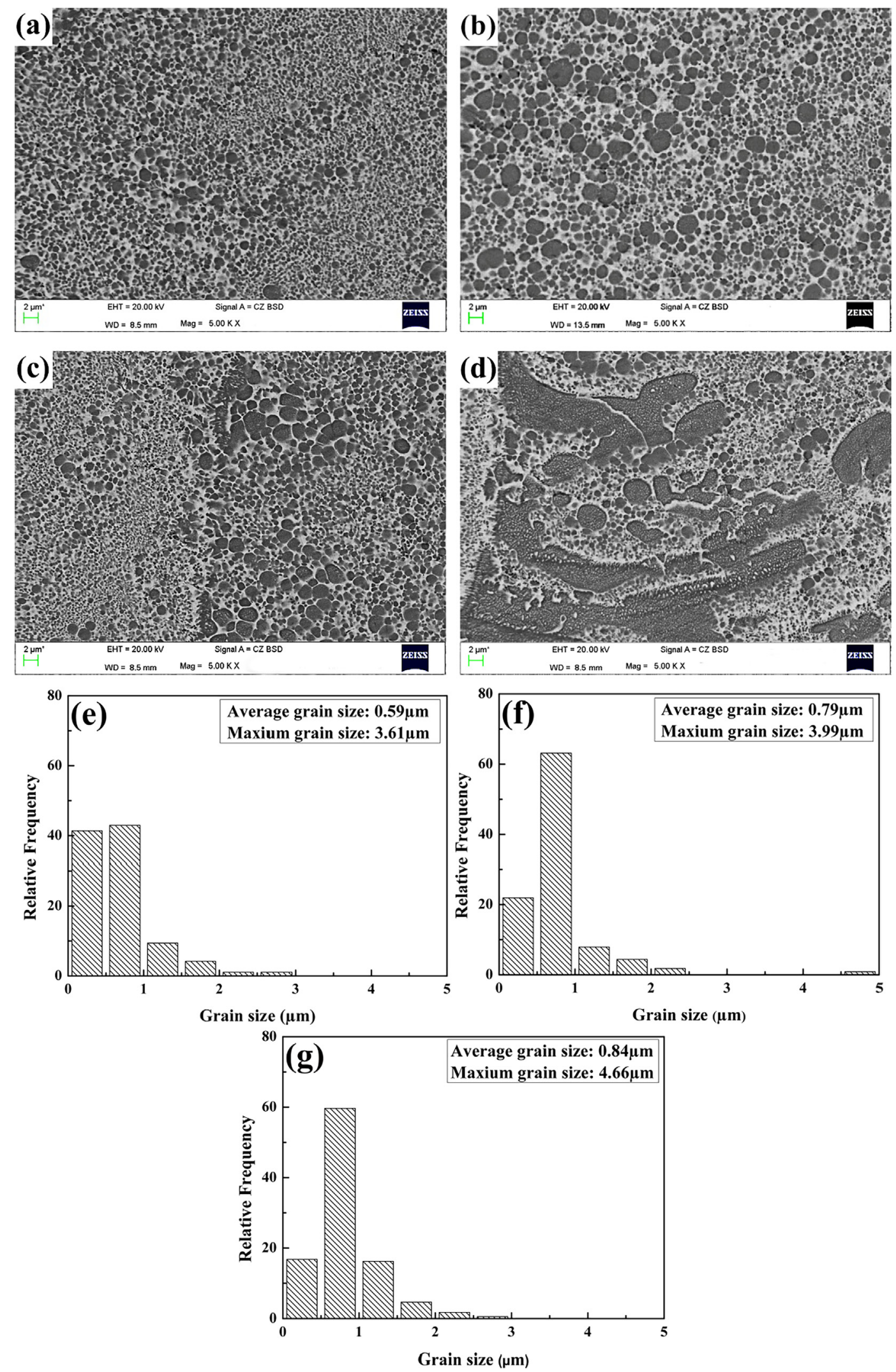

Fig. 5. Magnified image of the morphologies of $\mathrm{Cr}$ grains in Fig. 4a, (a) top of the melt pool, (b) middle of the melt pool, (c) overlapping zone of the melt pool (d) bottom of the melt pool and $(\mathrm{e}-\mathrm{g})$ the corresponding grain size distribution. 


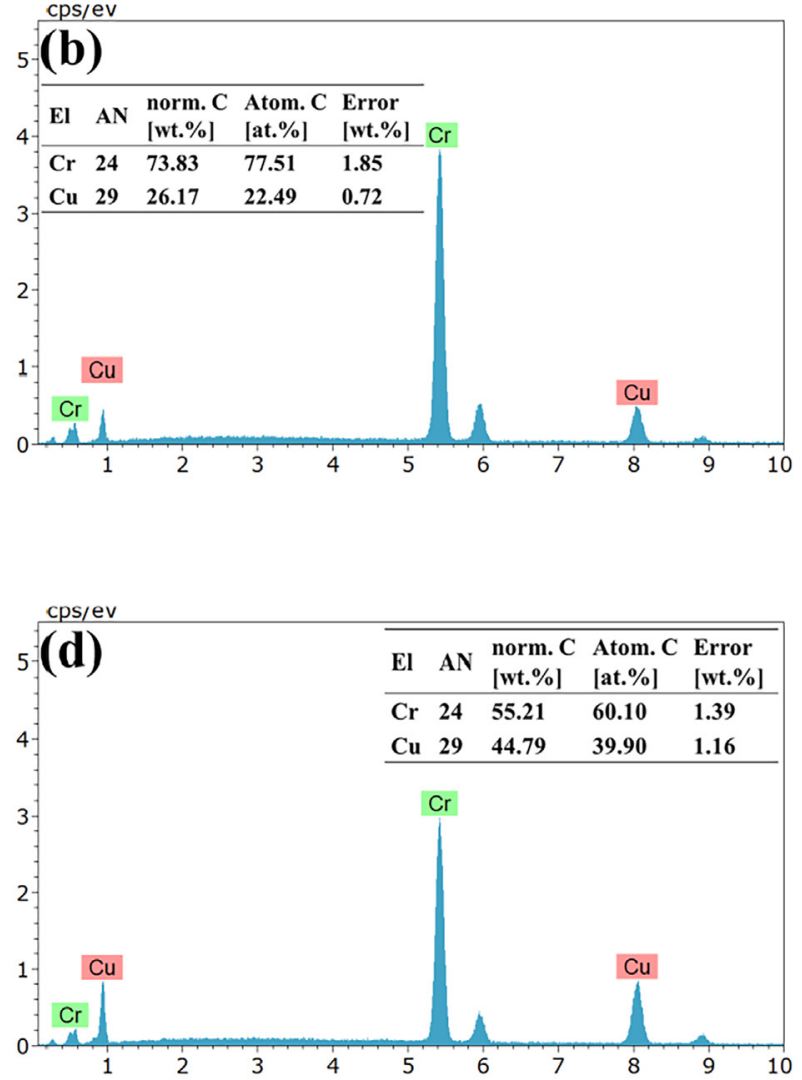

Fig. 6. Magnified image of (a) Cr-rich cluster in Fig. 4c, (b) the corresponding EDS analysis of point A (c) Cr-rich sheet in Fig. 4d, and (d) the corresponding EDS analysis of point B.

\section{Discussion}

\subsection{Parametric study}

The thermal diffusivity of $\mathrm{Cu}\left(1.1 \times 10^{-4} \mathrm{~m}^{2} / \mathrm{s}\right)$ is one order of magnitude lower than that of $\mathrm{Cr}\left(2.7 \times 10^{-5} \mathrm{~m}^{2} / \mathrm{s}\right)$, and the thermal diffusivity in $\mathrm{Cu}(394 \mathrm{~W} / \mathrm{m} \cdot \mathrm{K})$ is much faster than that in $\mathrm{Cr}(91 \mathrm{~W} /$ $\mathrm{m} \cdot \mathrm{K})$. Therefore, it is very important to select appropriate laser processing parameters for the complete melting of the melt layer, which determines whether the components in the molten pool can be mixed and solidified quickly to obtain the desired microstructure. When the low $\mathrm{E}$ was adopted during LSM, the temperature raise was relatively small, the temperature in the melt layer was above the melting point of $\mathrm{Cu}$ and below the melting point of $\mathrm{Cr}$, and the adjacent $\mathrm{Cr}$ phase absorbed the latent heat released from the solidified $\mathrm{Cu}$ phase, so the edges of the $\mathrm{Cr}$ phase were dissolved (denoted by arrow A in Fig. 3a). When the excessive $\mathrm{E}$ was adopted, the maximum temperature of the melt pool increased and there existed a sharp temperature gradient from the melt surface to the substrate. As depicted by arrow B, it revealed the occurrence of deep laser beam penetration around the center
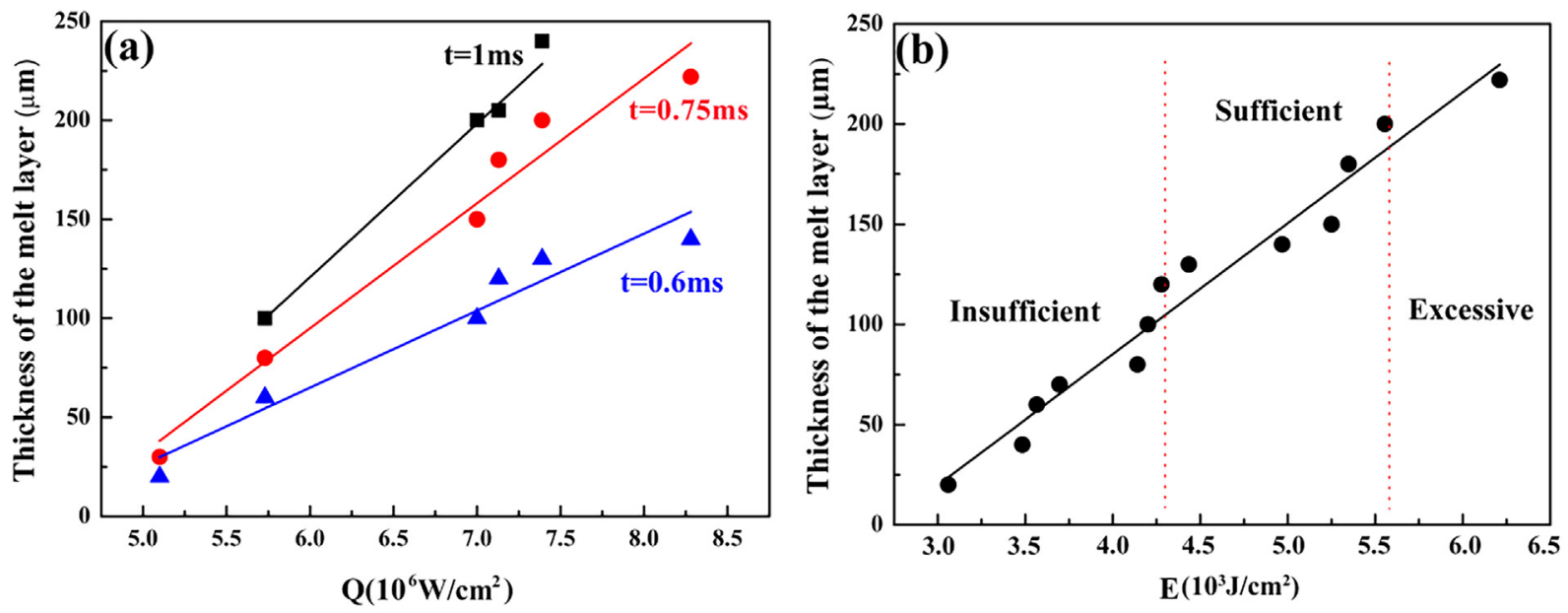

Fig. 7. Effect of (a) Q (laser power density) (b) E (laser fluence) on the depth of the refined layer. 


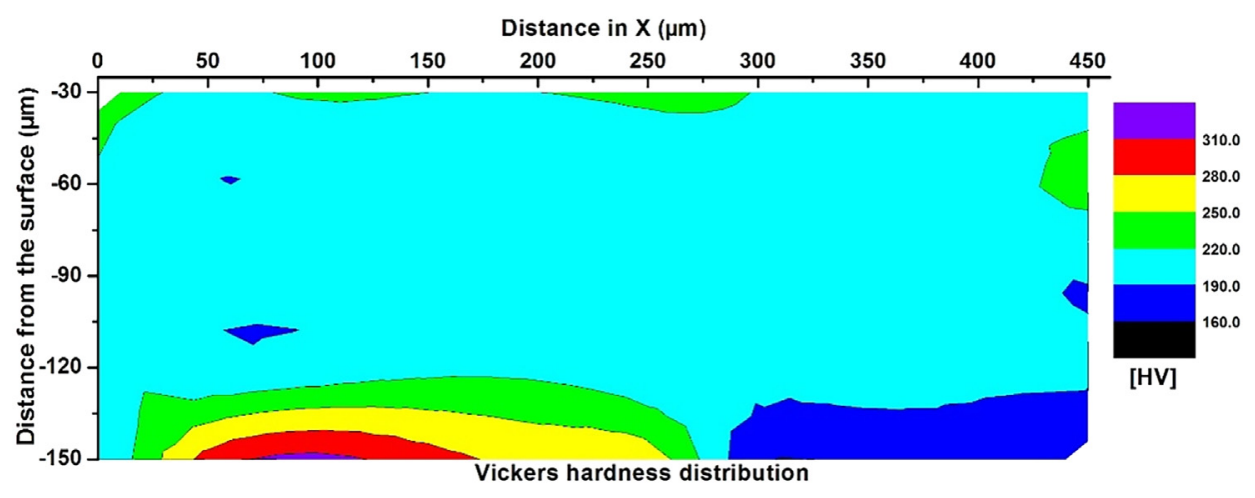

Fig. 8. Vickers hardness distribution in the refined layer.

of the laser beam, the temperature at the bottom of the melt pool was almost to the boiling point of $\mathrm{Cr}$. At the same time, it would take longer time to cool the melt pool and the convection became more intense. The longer time the solidification cost, the more completely the liquid phase separation resulting in the larger size of $\mathrm{Cr}$ phase. The appearance of the spherical shape $\mathrm{Cr}$ particles was beneficial for the improvement of the properties of $\mathrm{Cu}-\mathrm{Cr}$ alloy, while the large $\mathrm{Cr}$ sheets with irregular shapes were harmful to the performance of $\mathrm{Cu}-\mathrm{Cr}$ contacts. An appropriate range of $\mathrm{E}$ was crucial to obtain a refined and uniform distributed microstructure as shown in Fig. 7b. Only in the laser energy density range, the temperature of the $\mathrm{Cu}-\mathrm{Cr}$ melt was above the miscible metastable gap, then followed by sustainable inter diffusion and rapid solidification, melt separation was suppressed, and the desirable microstructure could be obtained.

\subsection{Microstructure evolution}

As is well known the cooling rate of LSM is on the order of $10^{3}-10^{8} \mathrm{~K} / \mathrm{s}$ [1], which can lead to a considerable dynamic supercooling of $\sim 150 \mathrm{~K}$ [13]. Generally, the supercooling of the $\mathrm{Cu}-\mathrm{Cr}$ immiscible alloys with $50 \% \mathrm{Cr}$ content is less than $27 \mathrm{~K}$ during the process of liquid phase separation (LPS) [14]. Therefore, when homogenous CuCr melt was cooled below the metastable miscible gap (MG), the melt decomposed into two mutual insoluble melts spontaneously, i.e., $\mathrm{Cu}-$ rich liquid $\left(\mathrm{L}_{\mathrm{Cu} \text {-rich }}\right)$ and $\mathrm{Cr}$-rich liquid $\left(\mathrm{L}_{\mathrm{Cr} \text {-rich }}\right)$. Since the Gibbs free energy of one liquid and one solid is higher than that of two liquids, the solidification of primary crystals stops at the beginning of LPS. Two different solidification procedures are described below:

General process: $L_{C u C r} \rightarrow L_{C u-r i c h}+S_{C r-r i c h} \rightarrow S_{C u-r i c h}+S_{C r-r i c h}$ LPS:
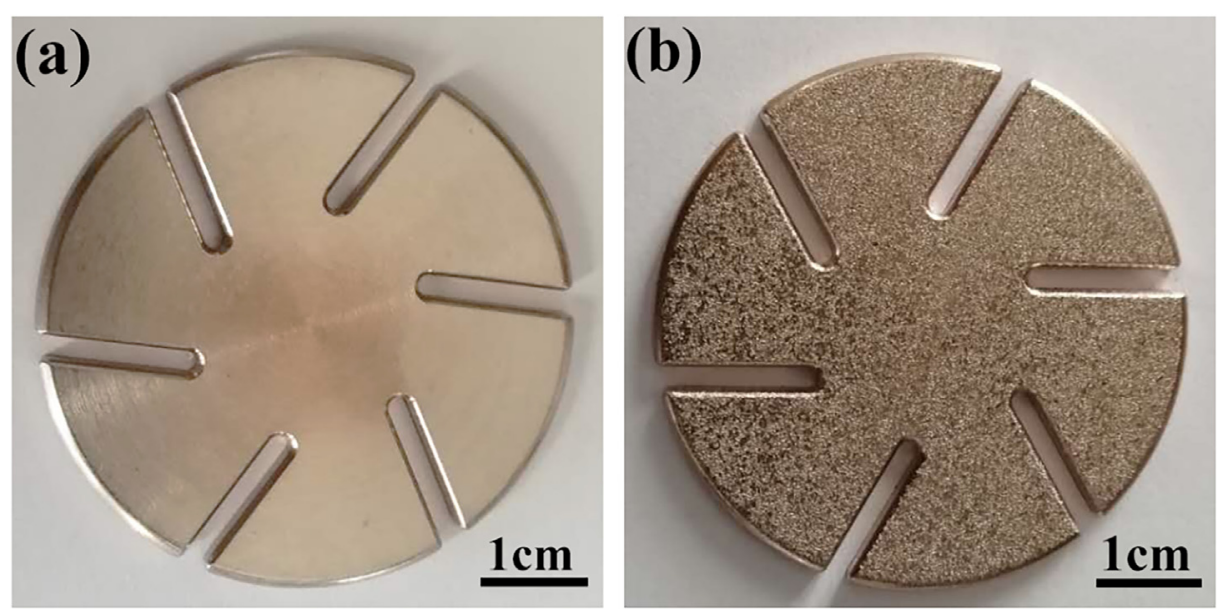

Fig. 9. Top-view of (a) untreated (b) LSM treated Cu-50Cr contacts.

$$
L_{\mathrm{CuCr}} \rightarrow L_{\mathrm{Cu}-\mathrm{rich}}+L_{\mathrm{Cr}-\mathrm{rich}} \rightarrow L_{\mathrm{Cu}-\mathrm{rich}}+S_{\mathrm{Cr}-\mathrm{rich}} \rightarrow S_{\mathrm{Cu}-\mathrm{rich}}+S_{\mathrm{Cr}-\mathrm{rich}}
$$

The two melts will follow their own solidification path to accomplish nucleation and growth. Critical energy required for nucleation was described by the following equations [15]:

$\Delta \mathrm{G}_{c}=\frac{16 \pi \gamma^{3} T_{m}^{2}}{3\left(L_{m} \Delta T\right)^{2}}$

where $\Delta \mathrm{G}_{c}$ is the formation work of the critical crystal nucleus, $\gamma$ is the surface energy per unit area of embryos, $T_{m}$ is the liquid temperature, $\Delta T$ is the supercooling of the melt, $L_{m}$ is the latent heat of liquid-solid transformation. According to the $\mathrm{Cu}-\mathrm{Cr}$ binary phase diagram, the formation work for nucleation of $L_{C r-r i c h}$ was lower than that of the $L_{C u-r i c h}$, suggesting that $L_{C r-r i c h}$ experienced a preferential nucleation. The $L_{C r-r i c h}$ spontaneously shrinks into big amounts of spherical particles due to the surface tension, and the solidified $\mathrm{Cr}$ spheroids were enveloped by the surrounding $\mathrm{Cu}$ melt, and then embedded in the $\mathrm{Cu}$ matrix which will solidify later [16]. As a result, the $\mathrm{Cr}$ particles preferably distributed in $\mathrm{Cu}$ matrix. The $\mathrm{Cr}$ particles with a spheroidal morphology dispersed in the $\mathrm{Cu}$ matrix with the average diameter $\sim 1 \mu \mathrm{m}$ evidenced the process of LPS, as shown in Fig. 5. The whole cooling process of the samples lasted only tens of milliseconds, even if the time for liquid cooling was neglected, such a short time could not allow nano-sized nuclei of a solid solution to grow to $\mathrm{Cr}$ particles with the diameter up to a few microns due to slow diffusion kinetics in the solid state. However, if the micron-sized $\mathrm{Cr}$ particles were nucleated from a supersaturated $\mathrm{Cu}-\mathrm{Cr}$ melt through the metastable LPS, they would be able to reach a size even of several micros within a few seconds due to a faster convection kinetics as well as collision-assisted coagulation in the liquid state.

As presented in Fig. 6, the collisions and coalescences between $\mathrm{Cr}$ 

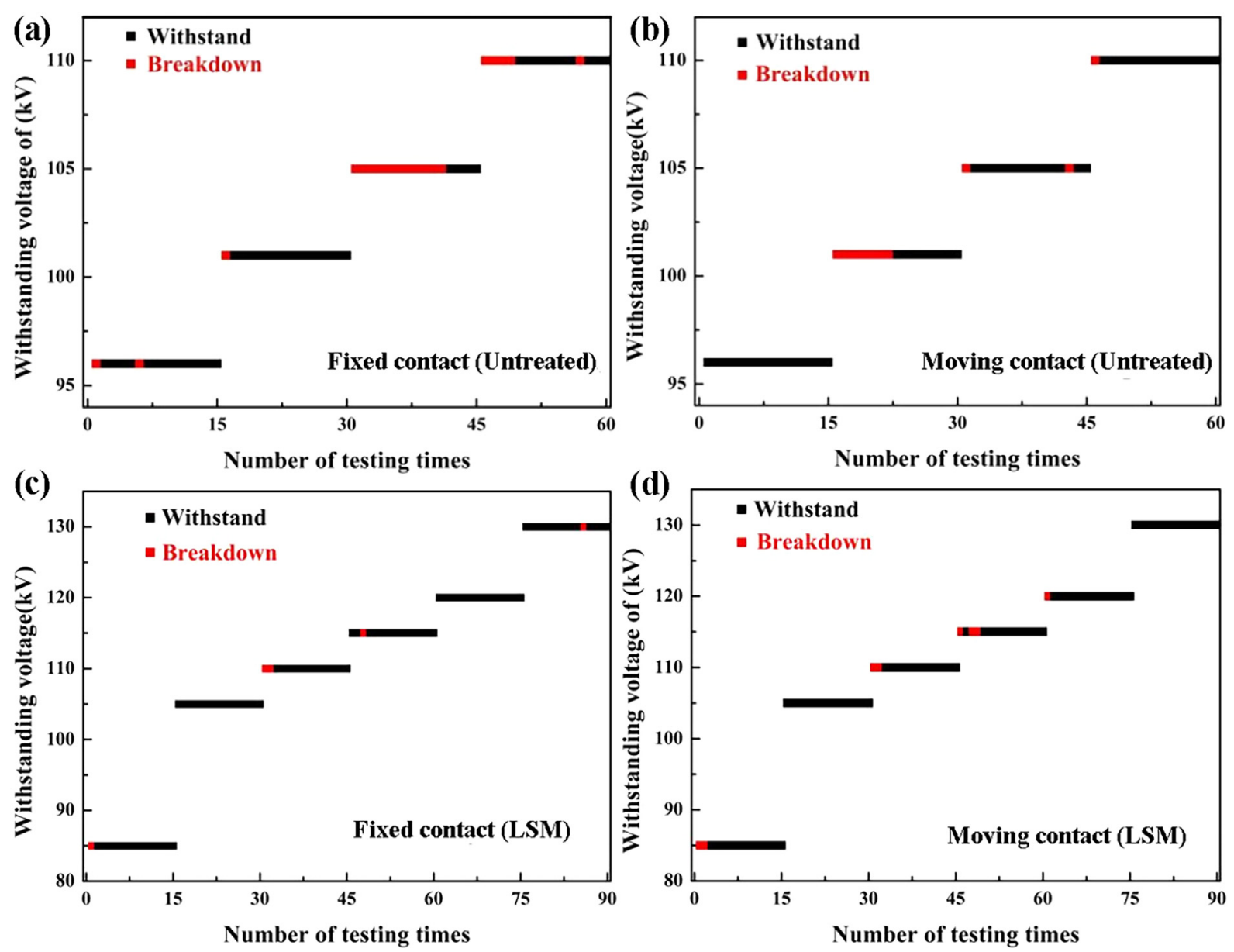

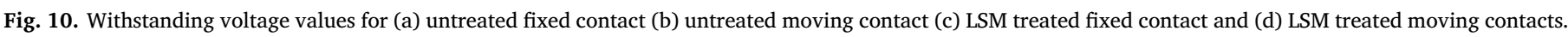

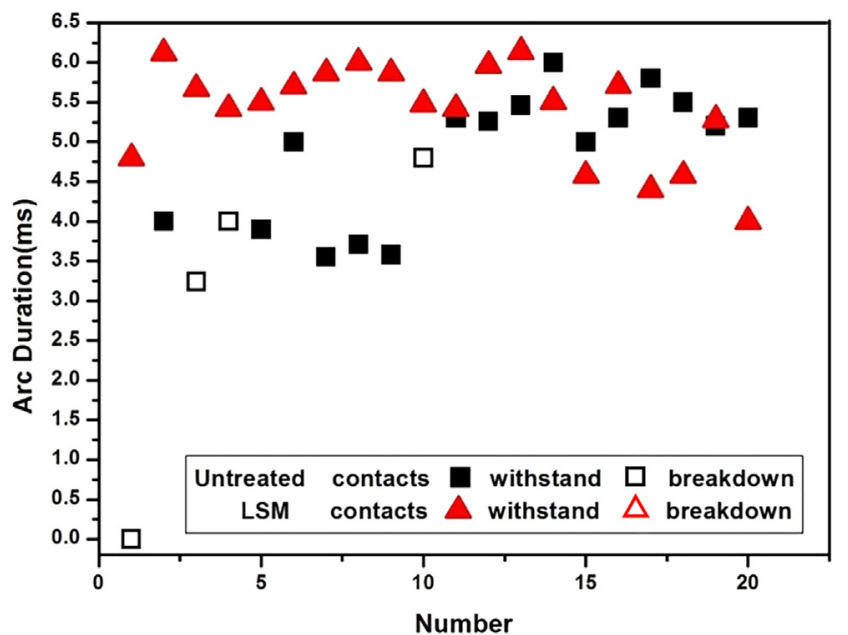

Fig. 11. The arc duration along with the switch-off operations up to twenty times, and failure or success for each operation. particles occurred frequently, resulting in an agglomeration trend to form Cr-rich sites. The $\mathrm{Cr}$-rich sites were also found in an electron beam irradiated $\mathrm{Cu}-30 \mathrm{Cr}$ alloy, which they attributed to the formation of some $\mathrm{Cu}_{\mathrm{x}}-\mathrm{Cr}_{1-\mathrm{x}}$ compounds [17]. However, the formation enthalpy was positive on the whole composition range indicating that there was little possibility for the existence of such compounds [18]. A more reasonable explanation for the formation of $\mathrm{Cr}$-rich sites was the fluid flow during rapid solidification [14]. In the process of LPS, the Cr particles were not stationary, instead, they were affected by various convection forces and gravity. The velocity of Marangoni motion $\left(v_{m}\right)$ and the Stokes motion $\left(v_{s}\right)$ are the two competitive factors. The velocity of the $\mathrm{Cr}$ particles controlled by Marangoni motion is given by Eq. (5) [19]:

$v_{m} \approx \frac{2 r}{3\left(3 \mu_{d}+2 \mu_{m}\right)} \cdot \frac{\partial \sigma}{\partial T} \cdot G$

where $r$ is the radius of the $\mathrm{Cr}$ droplet, $\mathrm{G}$ is the temperature gradient, $\mu_{d}$ and $\mu_{m}$ are viscosities of the $\mathrm{Cr}$ liquid droplet and the $\mathrm{Cu}$ liquid matrix, respectively, and $\frac{\partial \sigma}{\partial T}$ is the interfacial energy. When the size of the $\mathrm{Cr}$ phase decreased to $\sim 1 \mu \mathrm{m}$ and the value of the temperature gradient was up to $\sim 600 \mathrm{~K} / \mathrm{mm}$, the value of $v_{m} / v_{s}$ increased rapidly, the effect of gravity turned to be so small that the Stokes motion could be ignored [20]. Generally, the temperature gradient at the bottom of the melt pool

Table 2

Arc duration features of different samples.

\begin{tabular}{|c|c|c|c|c|}
\hline Sample & Ave, arc duration (ms) & Max, arc duration (ms) & Min, arc duration (ms) & Standard deviation of arc duration \\
\hline Untreated & 4.5 & 5.8 & 0 & 1.3 \\
\hline LSM & 5.3 & 6.1 & 4.0 & 0.6 \\
\hline
\end{tabular}


was larger than that at the other region. Obviously, the increase in temperature gradient which in turn can result in the increasing of $v_{m}$. Thus, the probability of collision and coalescence between the $\mathrm{Cr}$ spheroids increased correspondingly. Consequently, the average diameter of Cr-rich particles in the Cu matrix increased with an increase in the distance away from the surface, as shown in Fig. 4. Especially, at the bottom of the melt pool where the G was largest, the Cr-rich sheet appeared because of the fierce impingement and accumulation between Cr spheroids. According to Eq. (5), we can see that the larger the $\mathrm{Cr}$ particles, the faster the $\mathrm{v}_{\mathrm{m}}$. Therefore, the formation process of Cr-rich sites was as follows: when a larger $\mathrm{Cr}$ particle caught up with the smaller particle, the small spheroids were absorbed by the large ones and finally they combined with each other to form a new, even lager $\mathrm{Cr}$ rich particle.

$\mathrm{Cu}$ and $\mathrm{Cr}$ existed as two independent phases in the $\mathrm{Cu}-\mathrm{Cr}$ alloy, the two components won't undergo a solid-liquid phase transition at the same temperature. The process of melting and solidification happened at their respective melting points. At $1355 \mathrm{~K}$, the $\mathrm{Cr}$ phase is in the solid state, the latent heat is only part of $\mathrm{Cu}$. When the temperature rises to $2133 \mathrm{~K}$, the $\mathrm{Cu}$ phase is completely fused and only the latent heat of $\mathrm{Cr}$ is considered. As shown in Fig. 1, clearly, the Cr phase was fully melted in the $\mathrm{Cu}$ matrix. The latent heat of solid-liquid phase transition at different temperatures was listed in Table 3. The cooling rate for the LSM samples was calculated by Eq. (6) [21],

$\frac{\mathrm{dT}}{\mathrm{dt}}=-\frac{2 \pi \mathrm{Kv}\left(\mathrm{T}-\mathrm{T}_{0}\right)^{2}}{\mathrm{~A}\left(\mathrm{q}-2 \mathrm{r}_{\mathrm{B}} \mathrm{Z}_{\mathrm{m}} \mathrm{L}\right)}$

where $L$ is the latent heat of melting, $q$ is laser power, $r_{B}$ is the radius of laser beam, $\mathrm{z}_{\mathrm{m}}$ is the average thickness of the melt layer, $\mathrm{K}$ is thermal conductivity of the alloy, $\mathrm{T}$ and $\mathrm{T}_{0}$ are the melting temperature and room temperature, $\mathrm{A}$ is absorptivity for the laser beam, $\mathrm{v}$ corresponds to the laser scanning velocity. The value of A is obtained by Eq. (7) [22],

$\mathrm{A}=\frac{2 \pi \mathrm{Kr}_{\mathrm{B}} \mathrm{T}}{1.77 \mathrm{q}}$

For the calculation of the cooling rate, the laser scanning speed and the thickness of the melt layer and their respectively laser power, and $\mathrm{K}=244 \mathrm{~W} / \mathrm{m} \cdot \mathrm{K}, \mathrm{r}_{\mathrm{B}}=50 \mu \mathrm{m}, \mathrm{T}_{0}=288 \mathrm{~K}, \mathrm{v}=0.13 \mathrm{~m} / \mathrm{s}, \mathrm{q}=570 \mathrm{~W}$, $\mathrm{T}_{\mathrm{m}}=2133 \mathrm{~K}, \mathrm{z}_{\mathrm{m}}=165 \mu \mathrm{m}$ and $\mathrm{L}=1.45 \times 10^{9} \mathrm{~J} / \mathrm{m}^{3}$ were taken as input parameters. The calculated cooling rate for LSM sample was $5.98 \times 10^{6} \mathrm{~K} / \mathrm{s}$. Although the gathering tendency for Cr particles existed, the coagulations were suppressed by the high cooling rate. The existence time of the melt pool was so short that there was no sufficient time for the $\mathrm{Cr}$ particles to merge into larger ones. As a result, the mean diameter of the $\mathrm{Cr}$ phase in the melt layer was $\sim 1 \mu \mathrm{m}$. In order to obtain an even finer solidified microstructure, further research should be done on suppressing the growth of Cr-rich particles.

\subsection{Property characteristics}

\subsubsection{Microhardness}

The hardness depended mainly on the microstructure, since LSM provided grain refinement in the melt layer, the higher hardness was obtained. Hardness of $\mathrm{Cu}-\mathrm{Cr}$ alloy processed by different technologies was summarized in Table 4. It was evident that hardness was increased with the decrease of grain size, which showed an inverse correlation.

Table 3

Latent heat of $\mathrm{Cu}, \mathrm{Cr}$ and $\mathrm{Cu}-\mathrm{Cr}$ alloy.

\begin{tabular}{lll}
\hline Material & Density $\left(10^{3} \mathrm{~kg} / \mathrm{m}^{3}\right)$ & Latent heat of melting $/\left(\mathrm{J} \cdot \mathrm{m}^{3}\right)$ \\
\hline $\mathrm{Cu}$ & 8.9 & $1.82 \times 10^{9}$ \\
$\mathrm{Cr}$ & 7.2 & $2.89 \times 10^{9}$ \\
$\mathrm{Cu}-50 \mathrm{Cr}$ & 7.9 & $1356 \mathrm{~K}: 0.5 \times 1.82 \times 10^{9}$ \\
& & $2133 \mathrm{~K}: 0.5 \times 2.89 \times 10^{9}$ \\
\end{tabular}

Table 4

Comparison of the hardness of $\mathrm{Cu}-\mathrm{Cr}$ alloy processed by different technologies.

\begin{tabular}{lll}
\hline Condition & Vickers hardness (HV) & Reference \\
\hline LSM & $188-232$ & This work \\
Laser surface alloying & 120 & {$[22]$} \\
Arc-melt & 122 & {$[23]$} \\
\hline
\end{tabular}

Another reason for the enhancement of hardness could be the solid solubility of $\mathrm{Cr}$ in $\mathrm{Cu}$. For the rapid solidification could raise the solid solubility of $\mathrm{Cr}$ in $\mathrm{Cu}$, it was reasonable that a higher solid solubility contributed to the enhanced hardness. As a result, the microhardness of the refined layer was 2.8 times higher than that of the substrate due to crystal strengthening and solid solution strengthening (Fig. 8).

\subsubsection{Withstanding voltage and interruption capability}

As a kind of electrical contact material, the surface of $\mathrm{Cu}-\mathrm{Cr}$ alloy was burned by a high temperature vacuum arc to produce metal vapor, which supports the continuous arcing and realizes transient conversion from conductor to insulator (within $10 \mathrm{~ms}$ ). Therefore, there is an intrinsic relationship between the motion characteristics of arc and the microstructures of contact materials, especially the size, distribution and morphology of the $\mathrm{Cr}$ phase. The microstructure of the contacts material dominated the motions of cathode spots during the switching off operations. The electron emission current remarkably increases with the decrease of the work function at constant electric field intensity. The maximum work function of the close-packed plane $\mathrm{Cu}$ (111) is $0.13 \mathrm{eV}$ higher than that of $\mathrm{Cr}$ (1 110$)$ [24]. The electrons are more easily emitted from the $\mathrm{Cr}$ phase, so the first breakdown preferably ignited on the dielectrically weak $\mathrm{Cr}$ phase $[25,26]$. The $\mathrm{Cr}$ particle size of the untreated alloy was $\sim 100 \mu \mathrm{m}$, which was about 20 times bigger than that of conventional recognized cathode spot size $\sim 5 \mu \mathrm{m}$ [27]. Motions of cathode spot will be restricted on coarse Cr particles or jump back and forth over the large $\mathrm{Cr}$ phase. After the LSM treatment, the $\mathrm{Cr}$ particles on the surface were refined to a smaller average size $(\sim 1 \mu \mathrm{m})$ and a similar morphology to those of the cathode spots. So the spot migration pattern was transferred to fast continuous moving which led to a longer arc trace routine and faster motion speed, resulting in the uniform distribution of arc energy on the contact surface. It was also helpful to mitigate serious partial ablate of the surfaces and reduce the possibility of failures in switching off operations. As a result, surface of the contacts was able to withstand higher voltage $(130 \mathrm{kV})$.

As shown in Fig. 11 that all the failures of untreated contacts occurred with relatively lower arc duration, indicating that the arc duration affected the success or failure of each switching off operation. Vacuum arc was only fed by metal vapour evaporated from the contact surface. The effect of particle size on the metal vapour pressure was given by Kelvin's equation when considering the critical metal vapour as an ideal gas [27]:

$\mathrm{RT} \ln \frac{P(r)}{P(\infty)}=\frac{2 \sigma V}{r}$

where $P(r)$ is the vapour pressure, $P(\infty)$ is the vapour pressure of the flat interface, of $r$ is the radius of particle, $\sigma$ is the surface tension, $T$ is the temperature, and $\mathrm{V}$ is the mole volume. The vapour pressure $\mathrm{P}(\mathrm{r})$ increased with the decreasing in the $\mathrm{Cr}$ grain size. The higher the vapor pressure, the longer the metal vapor required to provide a steady current. At the same time, when the size of $\mathrm{Cr}$ phase decreases, with the certain value of arc energy, more heat input per unit area is transferred to the surrounding $\mathrm{Cu}$ phase with higher thermal conductivity, so more $\mathrm{Cu}$ phase will be heated and evaporated. Both the refined $\mathrm{Cr}$ phase and $\mathrm{Cu}$ phase matrix provide the metal vapor needed for arc ignition. Therefore, the refinement of the $\mathrm{Cr}$ phase of the $\mathrm{Cu}-\mathrm{Cr}$ alloy can greatly improve the stability and sustainability of the arc and reduce the chopping current. Therefore, fined-grained contacts owned a more 
stable and longer arc duration (increased by 18\%), and LSM contacts have successfully passed 20 consecutive switching off operations, as shown in Fig. 11.

\section{Conclusion}

LSM method was used to modify $\mathrm{Cu}-\mathrm{Cr}$ vacuum electrical contacts which were fabricated through the PM process. Laser surface melting produced a homogeneous melt layer, the microstructure of the layer was characterized by the refined spherical $\mathrm{Cr}$ spheroids and $\mathrm{Cr}$-rich sites embedded in $\mathrm{Cu}$ matrix. The hardness test, withstanding voltage test and the interruption capability test were performed to investigate the influence of grain refinement on the surface of $\mathrm{Cu}-\mathrm{Cr}$ contacts. The following results were obtained:

(1) The average diameter of $\mathrm{Cr}$ phase was effectively refined from hundreds of microns to few hundred nanometers, and dispersed in the melt layer with the thickness of up to $165 \pm 20 \mu \mathrm{m}$.

(2) In order to obtain a dispersed and refined microstructure, the optimal laser fluence range was from $4.3 \times 10^{3} \mathrm{~J} / \mathrm{cm}^{2}$ to $5.5 \times 10^{3} \mathrm{~J} /$ $\mathrm{cm}^{2}$.

(3) The gathering tendency for the Cr spheroids induced by LPS was suppressed by the high cooling rate $\left(5.98 \times 10^{6} \mathrm{~K} / \mathrm{s}\right)$ during LSM process.

(4) The microhardness of the refined layer increased to $198-232 \mathrm{HV}$, which was two times higher than that of the matrix.

(5) The withstanding voltage of the LSM contacts increased to $130 \mathrm{kV}$. Compared with the untreated contacts, the withstanding voltage value of the fixed and the moving contact increased to $28.7 \%$ and $35.4 \%$, respectively. The arc duration of LSM contacts increased by $18 \%$ resulting in successful successive 20 switching off operations.

\section{Acknowledgements}

The authors would like to acknowledge financial support from the Instrument Developing Project of the Chinese Academy of Sciences (No. yz201636) and the National Natural Science Foundation of China (No. 11672304, No. 11502269, No. 11272316 and No. 11272317).

\section{References}

[1] J.D. Majumdar, R. Galun, B.L. Mordike, I. Manna, Effect of laser surface melting on corrosion and wear resistance of a commercial magnesium alloy, Mater. Sci. Eng. A 361 (2003) 119-129.

[2] G. Yu, X. He, S. Li, Laser Manufacturing and its Application, National Defend Industry Press, China, 2016.

[3] K. Saeidi, X. Gao, Y. Zhong, Z.J. Shen, Hardened austenite steel with columnar subgrain structure formed by laser melting, Mater. Sci. Eng. A 625 (2015) 221-229.
[4] Y. Yao, X. Li, Y.Y. Wang, W. Zhao, G. Li, R.P. Liu, Microstructural evolution and mechanical properties of Ti-Zr beta titanium alloy after laser surface remelting, J. Alloys Compd. 583 (2014) 43-47.

[5] P.G. Slade, The Vacuum Interrupter: Theory, Design and Application, CRC Press, New York, 2008.

[6] C.D. Cao, T. Letzig, G.P. Gorler, D.M. Herlach, Liquid phase separation in undercooled Co-Cu alloys processed by electromagnetic levitation and differential thermal analysis, J. Alloys Compd. 325 (2001) 113-117.

[7] J. Gao, Y.P. Wang, Z.M. Zhou, M. Kolbe, Phase separation in undercooled Cu-Cr melts, Mater. Sci. Eng. A 449-451 (2007) 654-657.

[8] B.Q. Ma, J.Q. Li, Z.J. Peng, G.C. Zhang, Structural morphologies of Cu-Sn-Bi immiscible alloys with varied compositions, J. Alloys Compd. 535 (2012) 95-101.

[9] Z.M. Zhou, Y.P. Wang, J. Gao, M. Kolbe, Microstructure of rapidly solidified Cu25wt.\%Cr alloys, Mater. Sci. Eng. A 398 (2005) 318-322.

[10] X.G. Cui, X.N. Cheng, X.J. Xu, J.Z. Lu, J.D. Hu, Y.M. Wang, Microstructure and tensile properties of the sub-micron and nano-structured $\mathrm{Al}$ produced by laser surface melting, Mater. Sci. Eng. A 527 (2010) 7400-7406.

[11] M.R. Silva, P. Gargarella, T. Gustmann, W.J.B. Filho, C.S. Kiminami, J. Eckert, S. Pauly, C. Bolfarini, Laser surface remelting of a Cu-Al-Ni-Mn shape memory alloy, Mater. Sci. Eng. A 661 (2016) 61-67.

[12] IEC 62271-100E2. High-voltage switch-gear and control-gear. Part 100: Alternating current circuit-breakers, 2001

[13] X.Q. Dai, S.F. Zhou, M.F. Wang, J.B. Lei, M. Xie, H.N. Chen, C.X. Wang, T. Wang, Effect of substrate types on the microstructure and properties of $\mathrm{Cu} 65 \mathrm{Fe} 35 \mathrm{com}$ posite coatings by laser induction hybrid cladding, J. Alloys Compd. 722 (2017) 173-182.

[14] X. Wei, J.P. Wang, Z.M. Yang, Z.B. Sun, D.M. Yu, X.P. Song, B.J. Ding, S. Yang, Liquid phase separation of $\mathrm{Cu}-\mathrm{Cr}$ alloys during the vacuum breakdown, J. Alloys Compd. 509 (2011) 7116-7120.

[15] A. Munitz, A.M. Bamberger, S. Wannaparhun, R. Abbaschian, Effect of supercooling and cooling rate on the microstructure of Cu-Co-Fe alloys, J. Mater. Sci. 41 (2006) 2749-2759.

[16] H. Tanaka, A new coarsening mechanisms of droplet spinodal decomposition, J. Chem. Phys. 103 (1965) 2361-2364.

[17] A. Lamperti, P.M. Ossi, V.P. Rotshtein, Surface analytical chemical imaging and morphology of Cu-Cr alloy, Surf. Coat. Tech. 200 (2006) 6373-6377.

[18] L. Kaufman, Coupled phase diagrams and thermochemical data for transition metal binary systems-III, Calphad 2 (1978) 117-146.

[19] C.P. Wang, X.J. Liu, I. Ohnuma, R. Kainuma, K. Ishida, Formation of immiscible alloy powders with egg-type microstructure, Science 297 (2002) 990-993.

[20] Y. Yu, C.P. Wang, X.J. Liu, R. Kainum, K. Ishida, Thermodynamics and kinetics in liquid immiscible Cu-Cr-Si ternary system, Mater. Chem. Phys. 127 (2011) 28-39.

[21] M.F. Ashby, K.E. Easterling, The transformation hardening of steel surfaces by laser beams-I. Hypo-eutectoid steels, Acta Mater. 32 (1984) 1935-1948.

[22] A. Hirose, K.F. Kobayashi, Surface alloying of copper with chromium by $\mathrm{CO}_{2}$ laser, Mater. Sci. Eng. A 174 (1994) 199-206.

[23] R. Muller, Arc-melted $\mathrm{CuCr}$ alloys as contact materials for vacuum interrupters, Simens Forsch, Entwicklungsber 17 (1988) 105-111.

[24] H. Kawano, Theoretical evaluation of the effective work functions for positive-ionic and electronic emissions from polycrystalline metal surfaces, Appl. Surf. Sci. 254 (2008) 7187-7192.

[25] W.F. Rieder, M. Schussek, W. Glatzle, The influence of composition and Cr particle size of $\mathrm{Cu} / \mathrm{Cr}$ contacts on chopping current, contact resistance, and breakdown voltage in vacuum interrupters, IEEE. T. Comp. Pack. Man. 12 (1989) 273-283.

[26] Y. Wang, C. Zhang, H. Zhang, B. Ding, K. Lu, Effect of the microstructure of electrode materials on arc cathode spot dynamics, J. Phys. D. Appl. Phys. 36 (2003) 2649-2654.

[27] B. Jttner, Cathode spots of electric arcs, J. Phys. D. Appl. Phys. 34 (2001) R103-R123. 